\title{
Clinical Profile, Radiological Resolution and Risk Factors Associated with Community Acquired Pneumonia
}

\author{
Singh DS ${ }^{1}$, Shrestha NC $^{2}$, Joshi $A^{3}$
}

\begin{abstract}
Introduction: Pneumonia is a widespread and commonest infectious lung disease that causes inflammation which lead to reduced oxygenation. Indeed, it is the leading cause of child death in the world. The study was carried out to fine out the demographic, clinical characteristics and radiologic resolution of Pneumonia in children between two months to 16 years of age. Material and Methods: A prospective study done in 121 cases over 18 month period in patients admitted in paediatric department of Dhulikhel hospital. Demography, clinical profile, diagnosis, Down's scoring at presentation, response of treatment and risk factor for Community acquired pneumonia were analysed using descriptive statics. Chest radiography was done on admission and every two weeks until its complete resolution occurred. Results: Community acquired pneumonia was significantly common in children less than one year $(p=0.022)$. The common symptoms of Community acquired pneumonia observed in this study were cough (80\%) and fever (66\%). The total leukocyte count had low degree of association with pneumonia. More than half of patients (54.08\%) with community acquired pneumonia had radiographic resolution at two weeks. The respiratory distress was significantly high $(p<0.0001)$ in children who delayed to seek medical treatment in a health facility by three days. Anaemia, Iymphopenia, thrombocytopenia, sepsis and haemorrhagic pleural effusion were the clinical characteristics associated with fatal Community acquired pneumonia. Conclusion: Clinical presentations varied in Community acquired pneumonia with different age groups. Chest radiography was still the best investigation for the diagnosis of pneumonia and most of the radiological clearance occurred in two weeks.
\end{abstract}

Key words: Community acquired pneumonia, chest radiography

\section{Introduction}

$D$ neumonia is an acute illness in which the alveolar air spaces of the lung become inflamed and filled with fluid and white blood cells, giving rise to the appearance of consolidation on the chest radiograph. In developing countries, where patients are often treated
${ }^{1}$ Dr Srijana Dongol Singh, MBBS, MD, Associate Professor, ${ }^{2} \mathrm{Dr}$. Narayan Charan Shrestha, MBBS, MD, Lecturer, ${ }^{3} \mathrm{Dr}$. Anish Joshi, MBBS, $M D$, Lecturer. All from the Department of Paediatrics, Dhulikhel Hospital, Kathmandu University Teaching Hospital, Dhulikhel, Kavre, Nepal.

\section{Address for correspondence \\ Dr. Srijana Dongol Singh, Associate Professor Department of Paediatrics, Dhulikhel Hospital Kathmandu University Teaching Hospital Dhulikhel, Kavre, Nepal \\ Tel No; +9779818073553 \\ E-mail: docsrijana@yahoo.com}

\section{Acknowledgements: None}

Funding: Nil

Conflict of Interest: None

Permission from IRB: Institutional Review committee of Kathmandu University School of Medical Science.

\section{How to cite}

Singh DS, Shrestha NC, Joshi A. Clinical Profile, Radiological Resolution and Risk Factors Associated with Community Acquired Pneumonia. J Nepal Paediatr Soc 2018;38(1):813.

doi: http://dx.doi.org/10.3126/jnps.v38i1.18854

This work is licensed under a Creative Commons Attribution 3.0 License.

\section{(c) (i)}


without seeing a doctor, the World Health Organization $(\mathrm{WHO})^{1}$ defines clinical pneumonia simply as an acute episode of cough or difficulty breathing associated with an increased respiratory rate. Most recently, the $\mathrm{WHO}^{2}$ has also pioneered the standardized interpretation of chest $x$-ray to define bacterial pneumonia. (i.e. signs of alveolar consolidation and/or pleural effusion)

Nearly one to two million children younger than five years die every year from pneumonia ${ }^{3}$. In Nepal, annual incidence of pneumonia in under-five year's children is $90 / 1000$. This incidence was found in2006 survey. ${ }^{4}$ Another Nepal demographic health survey 2011/ $2012^{5}$, done by Ministry of Health and Population, has also shown similar. It affects all paediatric age groups, though the highest incidence is in the underfive years ${ }^{6}$. Anaemia, lymphopenia, thrombocytopenia, sepsis and haemorrhagic pleural effusion were the clinical characteristics associated with fatal Community acquired pneumonia ${ }^{7}$.

Although this is a leading cause of under five children mortality, the research done in Nepal on this topic is very limited. The aim of this study is to find out the demographic, clinical characteristics and radiological resolution of Community acquired pneumonia. The clinical characteristics associated with Community acquired pneumonia were also studied

\section{Material and Methods}

This is a prospective study done for a period of one and half years from December 2014 to May 2016. All children from two month to 16 years who were admitted in Paediatric ward of Dhulikhel hospital with clinically diagnosed and radiologically confirmed cases of pneumonia were included in this study. Every case was subjected to a detailed history and clinical examination, followed by relevant investigations. All cases admitted from emergency department and sick child admitted from OPD, complete blood count and blood culture were sent. On admission, every day after admission and the time of discharge Downs' score was obtained. Downs Scoring System ${ }^{8}$ is an index designed to objectively assess the clinical severity of respiratory distress. The scores have therapeutic and prognostic significance but are not as reliable as blood gas measurements. They are to be used as an adjunct to (not as a substitute for) blood gas determinations. Downs Scoring System was shown below.

The patients were followed every day for the response to the treatment till the child cured. The questionnaire contained identification, clinical profile, and investigation, response to drug and radiological response. Written informed consent was taken from the parents before enrolling them in this study after a careful and complete explanation of the study and purpose. Patients were followed for a maximum of three months' time. At each follow up visit in two weeks interval, physical examination was done and repeated chest radiography till it became normal. All chest radiographs were re-evaluated by an experienced radiologist. The Institutional review committee approved the study.

\section{Results}

A total of 121 patients with community acquired pneumonia were enrolled where $35.5 \%$ were females and $64.5 \%$ males. In the present study as shown in Table 1, the incidence of pneumonia was higher among children less than five years $(n=81)$, out of which 44 (36.34\%) were infants and $37(30.57 \%)$ were between 1-5 years. Here, 40 (33.05\%) were more than 5 years.

The most common symptoms among all age group was cough, observed in total $80 \%$, which was most significantly common in children less than one year $(p=0.022)$. The next common presenting symptom was fever $72 \%$, shortness of breath $38 \%$, common cold $38 \%$. Chest pain and myalgia were significantly seen in children more than five years with $p$-value of 0.001 and.003 respectively. Among the clinical sign, crepitation were heard in $72.72 \%$, decreased air entry in $51.23 \%$ and rhonchi was heard in $18.18 \%$ cases. Rhonchi was significantly observed in children less than one year with $p$-value of 0.025 .

\section{Downs Score for evaluation of respiratory Distress}

\begin{tabular}{lccc}
\hline Downs Score & $\mathbf{0}$ & $\mathbf{1}$ & $\mathbf{2}$ \\
\hline Cyanosis & None & Cyanotic in air & Cyanotic in $40 \% \mathrm{O}_{2}$ \\
\hline Retraction & None & Mild & Severe \\
\hline Grunting & None & Audible with stethoscope & Audible without stethoscope \\
\hline Air entry & Clear & Delayed or decreased & Barely audible \\
\hline Respiratory Rate & 60 & $60-80$ & 80 or apneic episodes \\
\hline
\end{tabular}

$>4=$ Clinical respiratory distress

$>8=$ Impending respiratory failure 
The complete blood count was done in total 95 Cases where $35.8 \%$ had high white blood cell count and $30.9 \%$ had high neutrophil count. Increased ESR was noted in $11.8 \%$ children with pneumonia. Blood cultures were obtained from $40(33.1 \%)$ children. Overall, the prevalence of bacteremia (blood culture positive) was $9.9 \%$. Among the culture positive cases, $75 \%$ has Streptococcus pneumoniae followed by Klebsiella in $25 \%$ cases.

Consolidation was more prevalent in the right than left lung (100Vs11), and was most frequent in right middle zone $47.9 \%$ followed by right upper zone $22.3 \%$ and then in right lower zone $12.4 \%$. Bronchopneumonia was observed in $8.3 \%$ cases shown in Table 3. Pleural effusion with consolidation was seen in $5.78 \%$ children. Six $4.95 \%$ children had consolidation with collapse of lung.

The radiographic resolution was slightly slower in patients with pleural effusion. A total of 121 patients with CAP, $80.99 \%$ had regular follow up in every two weeks with chest x-ray till complete resolution. After two weeks follow-up, 53/98 (57.6\%) had complete radiographic resolution. After six weeks follow-up, 90/98 (91.83\%) had complete radiographic resolution. None of the patients developed deterioration of chest radiography during the follow up period.

The median delay from the onset of illness to the time seeking treatment in a health facility was 5.5 days (Table 5). Twenty six percent cases sought treatment within two days, $66.11 \%$ to $3-7$ days and $7.3 \%$ took more than eight days. Children who delayed to seek medical treatment in a health facility by three days were more likely to present with moderate to severe respiratory distress with high significance $(p=0.0001)$.

Out of 121 patients, 119 (98.34\%) patients improved and were discharged. Three $(2.47 \%)$ patients died. Among all deaths, one occurred due to sepsis with pulmonary haemorrhage and two were caused by sepsis with multiple organ failure. All of them at the time of presentation had anaemia, leukopenia, lymphopenia and thrombocytopenia.

Table 1: Age and Sex Distribution of community acquired Pneumonia

\begin{tabular}{|c|c|c|c|c|c|c|c|}
\hline & & \multicolumn{4}{|c|}{ Sex } & \multicolumn{2}{|c|}{ Total } \\
\hline & & \multicolumn{2}{|c|}{ Male } & \multicolumn{2}{|c|}{ Female } & \multirow{2}{*}{ Total } & \multirow{2}{*}{$\%$} \\
\hline & & Total & $\%$ & Total & $\%$ & & \\
\hline \multirow{4}{*}{ Age } & $<1$ Year & 24 & $54.5 \%$ & 20 & $45.5 \%$ & 44 & $100.0 \%$ \\
\hline & $1-5$ years & 24 & $64.9 \%$ & 13 & $35.1 \%$ & 37 & $100.0 \%$ \\
\hline & $>5$ Years & 30 & $75.0 \%$ & 10 & $25.0 \%$ & 40 & $100.0 \%$ \\
\hline & Total & 78 & $64.5 \%$ & 43 & $35.5 \%$ & 121 & $100.0 \%$ \\
\hline
\end{tabular}

Table 2: Clinical profile of CAP in different age group

\begin{tabular}{|c|c|c|c|c|c|}
\hline \multirow{2}{*}{ Clinical Profile } & \multicolumn{3}{|c|}{ Age } & \multirow{2}{*}{ Total } & \multirow{2}{*}{$p$-value } \\
\hline & $<1$ year & $1-5$ years & $>5$ years & & \\
\hline 1. Fever & 26 & 26 & 28 & 80 & 0.46 \\
\hline 2. Headache & 2 & 5 & 13 & 20 & 0.002 \\
\hline 3. Cough & 41 & 26 & 30 & 97 & 0.022 \\
\hline 4. Nausea/Vomiting & 13 & 7 & 8 & 28 & 0.448 \\
\hline 5.Common cold & 18 & 17 & 11 & 46 & 0.221 \\
\hline 6. Anorexia & 11 & 12 & 13 & 36 & 0.688 \\
\hline 7. Myalgia & 0 & 1 & 7 & 8 & 0.003 \\
\hline 8. Chest pain & 0 & 7 & 15 & 22 & 0.001 \\
\hline 9. Dyspnoea/SOB & 19 & 15 & 13 & 47 & 0.585 \\
\hline 10. Effusion/empyema & 1 & 1 & 5 & 7 & 0.084 \\
\hline 11. Collapse lung & 2 & 2 & 2 & 6 & 0.984 \\
\hline 12. Sepsis & 0 & 0 & 1 & 1 & 0.360 \\
\hline 13. Decrease air entry & 21 & 19 & 22 & 62 & 0.791 \\
\hline 14. Crepitation & 35 & 27 & 24 & 86 & 0.136 \\
\hline 15. Rhonchi & 12 & 8 & 2 & 22 & 0.025 \\
\hline
\end{tabular}


Table 3: Distribution of lobar pneumonia according to zone involved in roentgenogram.

\begin{tabular}{ccc}
\hline Distribution of lobar pneumonia & Total $(\mathbf{n = 1 2 1 )}$ & Percent (\%) \\
\hline Rt. Upper Zone & 27 & 22.3 \\
\hline Rt. Middle Zone & 58 & 47.9 \\
\hline Rt. Lower Zone & 15 & 12.4 \\
\hline Lf. Upper Zone & 6 & 5.0 \\
\hline Lf. Middle Zone & 3 & 2.5 \\
\hline Lf. Lower Zome & 2 & 1.7 \\
\hline Broncho Pneumonia & 10 & 8.3 \\
\hline Total & $\mathbf{1 2 1}$ & $\mathbf{1 0 0 . 0}$ \\
\hline
\end{tabular}

Table 4: Pattern of Resolution of Radiological abnormalities associated with CAP.

\begin{tabular}{ccc}
\hline Duration of radiological resolution & Total $(\mathbf{n = 9 8 )}$ & Percentage (\%) \\
\hline 2 weeks & 53 & $54.08 \%$ \\
\hline 4 weeks & 7 & $7.14 \%$ \\
\hline 6 weeks & 30 & $30.61 \%$ \\
\hline 8 weeks & 6 & $6.12 \%$ \\
\hline 10 weeks & 1 & $1.02 \%$ \\
\hline 12 weeks & 1 & $1.02 \%$ \\
\hline
\end{tabular}

Table 5: Relation between the duration of health seeking time to the hospital and Down' Scoring

\begin{tabular}{|c|c|c|c|c|c|}
\hline \multirow{2}{*}{$\begin{array}{l}\text { Health seeking } \\
\text { time to hospital }\end{array}$} & \multicolumn{3}{|c|}{ Down' Scoring Group } & \multirow{2}{*}{ Total } & \multirow{2}{*}{$p$-value } \\
\hline & $0-3$ & 4-7 & $>8$ & & \\
\hline $1-2$ & 31 & 1 & 0 & 32 & .000 \\
\hline $3-7$ & 64 & 16 & 0 & 80 & \\
\hline$>8$ & 0 & 7 & 2 & 9 & \\
\hline Total & 95 & 24 & 2 & 121 & \\
\hline
\end{tabular}

\section{Discussion}

The study identified a significant proportion of under-five pneumonia burden with male and female ratio of 1.69:1. A study conducted on children hospitalized with pneumonia in Dhaulagiri Zonal Hospital of Nepal showed male to female ratio of $1.5: 1$ with a significant proportion of the under-five pneumonia burden. ${ }^{9}$ The same finding of health disparity being associated with higher pneumonia cases among hospitalized male children than in female has been reported by the studies conducted in Bangladesh ${ }^{10,11}$, where the male female ration were $2: 1$ and 1.4:1 respectively. This could also be due to higher rates of care seeking for male children than for female children, giving strong preference for sons in the south Asian regions ${ }^{12}$.

The common symptoms of CAP, observed in this study was consistent with other studies where Shamo'on data showed, the most sensitive and specific symptoms for prediction of pneumonia was cough in $71 \%$, fever in $70 \%$ and fast breathing in $65 \%$ children $^{13}$. Another study done in Manipal Teaching hospital ${ }^{14}$ also showed, the commonest mode of presentation to be cough $76 \%$ followed by fever in $64 \%$. All the cases of CAP had radiological confirmation with consolidation in one or multiple lobes. On the basis of roentgenogram, right lung was involved in $82.6 \%$ cases in which right middle zone were most frequently involved in $47.9 \%$ children. This is because of large diameter and more vertical direction of the right main bronchus. Ude data ${ }^{15}$ showed, right lung involvement in $79.0 \%$ of children but in contrast right upper zone consolidation was much higher around $37.0 \%$ of children. Another retrospective study done by $\mathrm{P}$ Rijal ${ }^{16}$ in Nepal Medical college also showed right sided lobar pneumonia in $60.6 \%$ and right middle zone was most commonly involved in $42.4 \%$ but in contrast left lower zone in $33.3 \%$ The incidence of consolidation with effusion $(5.7 \%)$ and atelectasis (4.9\%), was almost similar in comparison to the previous study done by $\mathrm{P}$ Rijal ${ }^{16}$ where incidence of consolidation with effusion was $8.3 \%$ and with atelectasis was $4.1 \%$.

The radiographic resolution seen in the present study is comparable to previous study ${ }^{17}$ that reported radiological cure rate of $50.6 \%$ after two weeks and $66.7 \%$ after four weeks of diagnosis of CAP. This is 
also comparable to previous studies ${ }^{18,19}$ that reported radiological cure rates of $35.1 \%$ to $87 \% 3-4$ weeks after diagnosis of CAP.

Similar to our study other authors Kumar $\mathrm{A}^{19}$ and Lakhani $\mathrm{D}^{20}$ also reported high count of $48.5 \%$ and $43.8 \%$ respectively. These all studies also suggest that total leukocyte count has low degree of association with pneumonia. Blood culture was positive in $30 \%$ cases (among those cases whose blood culture was sent) which was higher in comparison to other studies ${ }^{20,21}$ where positive blood culture where seen in $6.1 \%$ and $7.1 \%$ respectively. This may be due to late presentation in our country. In the present study blood culture was positive usually in children who were sick for more than five days without any treatment outside and admitted in PICU with sepsis. Streptococcus pneumonia was the commonest bacteraemia seen in Pneumonia. Studies conducted in Manipal Teaching Hospital ${ }^{14}$ and Children's hospital of Philadelphia ${ }^{22}$ had shown, the Streptococcus pneumoniae being commonest organism isolated in blood.

Children who delayed to seek medical treatment in a health facility by three days or more were more likely to present with moderate to severe respiratory distress. This finding was consistent with a study in Kenya ${ }^{23}$ that found median duration of illness before care is sought to be four days and maximum number of patients presented with in 3-7 days with moderate to severe respiratory distress. Another study in Uganda ${ }^{24}$ also found the median duration of illness before care is sought to be seven days and more likely to present with severe pneumonia.

Among the clinical characteristics, severe CAP was associated mainly with initial presentation of anaemia, lymphopenia, thrombocytopenia, sepsis and haemorrhagic pleural effusion. This finding was consistent with the study done by Wang in Taiwan ${ }^{7}$ where fatal CAP was associated mainly with initial presentation of anaemia, lymphopenia, thrombocytopenia, sepsis and disseminated intravenous coagulopathy.

\section{Conclusion}

The incidence of pneumonia was higher among children less than five years. The most common symptom was cough and fever. The laboratory investigation like total count, differential leukocyte count and blood culture has low degree of association with pneumonia. Chest radiography is an important diagnostic tool in patients suspected of having lower respiratory tract infection to confirm or exclude a diagnosis of pneumonia. Consolidation was more prevalence in right middle zone. Radiographs are not always recommended for routine follow-up in patients that has clinically improved.

\section{References}

1. WHO Programme for control of Acute Respiratory Infection 1990. Acute respiratory infection in children: case management in small hospital in developing countries. A manual for doctors and other senior health workers. WHO. Geneva, Switzerland.74pp. Document Number: 185594

2. Cherian T, Mulholland K E, Carlin B J, Harald O, Amin $R$ et al. Standardized interpretation of pediatric chest radiographs for the diagnosis of pneumonia in epidemiological studies. Bull WHO 2005;83(5):353359. DOI: /S0042-96862005000500011

3. United Nations Inter-Agency Group for child Mortality Estimation. Levels and trends in child mortality report 2012. United Nations children's Fund.

4. Basnet S, Adhikari RK, Gurung CK. Hypoxia in children with pneumonia and its clinical predictors. Indian $J$ Pediatr 2006; 73(9):777-81.

5. Ministry of Health \& Population, New ERA ICF International Inc. Nepal demographic health survey 2011/2012.

6. Zimmerman DR, Kovalski N, Nahir B. Diagnosis of childhood pneumonia: clinical assessment without radiological confirmation may lead to overtreatment.
Pediatr Emerg Care 2012;28(7):646-9. DOI: 10.1097/ PEC.0b013e31825cfd53

7. Wang LJ, Mu SC, Lin CH,Lin MI, Sung TC. Fetal community-acquired pneumonia: 18 years in a medical center. Pediatr Neonatol 2013;54(1):22-7. DOI: 10.1016/j.pedneo.2012.11.003

8. Downess JJ, Vidyasagar D, Baggs TR et al. Respiratory distress syndrome of newborn infants. New clinical scoring system with acid base and blood gas correlations. Clin Pediatr 1970; 9:325-331. DOI: 10.1177/000992287000900607

9. Banstola A, Banstola A. The Epidemiology of Hospitalization for pneumonia in children under five in the rural western region of Nepal: A Descriptive study. PLOS one 2013;8(8) e71311. DOI: https://doi. org/10.1371/journal.pone.0071311

10. Akbar MS, Ehsan A, Ali CMH. Clinical Profile and Management of Acute respiratory Infection at Dhaka Shishu (children) Hospital, Bangladesh. J Child Health 1992;16:5-8. DOI: http://dx.doi.org/10.3329/nimcj. v7i1.25703

11. Wahed Ma, Islam MA, Khondakar P,Hague MA. Effect of micronutrients on morbidity \& duration of hospital stay in childhood pneumonia. Mymensingh Med $J$ 2008;17(2):77-83. 
12. Pandey A, Sengupta PG, Mandal SK. Gender differences in health care seeking during common illness in a rural community of West Bengal, India. $J$ Health Popul Nutr 2002; 20:306-11.

13. Shamoon $\mathrm{H}$, Hawamdah $\mathrm{A}$, Haddadin $\mathrm{R}$, Jmeian $\mathrm{S}$. Detection of pneumonia among children under six years by clinical evaluation. Health J 2004;10:482-7.

14. R Shrestha, N Paudel, B Barakoti, D Dhungana, P Sharma. Etiology and Clinical profile of inpatients with community acquired pneumonia in Manipal Teaching hospital, Pokhara, Nepal. Nepal J Med Sci 2012;1(2):84-8. DOI: http://dx.doi.org/10.3126/njms. v1i2.6605

15. Ude $\mathbf{W H}$. Roentgenologic studies in early lobar pneumonia. Amer J Roent 1931; 26:691.

16. P Rijal, A Sharma, S Shrestha, S Upadhyay. Profile of acute lower respiratory tract infection in children under fourteen years of age at Nepal Medical College Teaching Hospital (NMCTH). Nepal Med Coll J 2011;13(1):58-61.

17. Mittle RI, Schwab RJ, Duchin JS, Goin JE, Albeida SM, Miller WT. Radiographic resolution of community acquired pneumonia. Am J Respir Crit Care Med 1994;149(3pt 1):630-3. DOI: 10.1164/ ajrccm.149.3.8118630

18. Solh AA, Aquilina AT, Gunen H, Ramadan F. Radiographic resolution of community -acquired bacterial pneumonia in the elderly. J Am Geriatr Soc 2004;52:224-9.
19. Kumar A, Lakhani D. Correction of Clinically suspected Community Acquired Pneumonia(CAP) with reference to chest radiograph \& laboratory parameters in rural Set up. New Indian J Surg 2011;2(4):270-271.

20. Lakhani D, Muley P. The association of positive chest radiograph and laboratory parameters with community acquired pneumonia in children. J Clin Diagn Res 2013;7(8):1629-31.DOI: 10.7860/ JCDR/2013/5132.3222

21. Ferrero F, Nascimento-carvalho $\mathrm{CM}$, Cardoso MR, Camargos P, March MF, Berezin E, et al. Radiographic findings among children hospitalized with severe community-acquired pneumonia. Pediatr Pulmonol 2010;45(10):1009-13. DOI: 10.1002/ppul.21287.

22. Shah SS, Dugan MH, Bell LM, Grundmeier RW, Florin $T A$, Hines EM, et al. Blood cultures in the emergency department evaluation of childhood pneumonia. Pediatr Infect Dis J 2011;30(6); 475-9. DOI: 10.1097/ INF.0b013e31820a5adb.

23. Dickens O, Gideon K, Evans A, Jared O. Risk factors of severe pneumonia among children aged 5-29 months in western Kenya: a case control study. Pan African Med J 2012;13(5):3-13.

24. Kallander $\mathrm{K}$, Hildenwall $\mathrm{H}$. Delayed care seeking for fatal pneumonia in children aged under five years in Uganda: a case series study. Bull WHO 2008;86(5)33238. DOI: 10.2471/BLT.07.049353. 